\title{
Editorial zum Schwerpunkt: Menschenwürde
}

Seit der Entscheidung zum Luftsicherheitsgesetz vom 15. Februar $2006^{1}$ ist die Debatte zur Menschenwürde reaktiviert, auf eine spontane, fast möchte man sagen eine strafrechtliche Art. Das hat nicht zuletzt mit dem Gegenstand zu tun, denn das Recht für den Staat zum Töten Unschuldiger - und sei es zu einem noch so guten Zweck ruft erst einmal spontane Empörung hervor. Das merkt man einigen, vor allem den strafrechtlichen Beiträgen an, wenn Menschenwürde - etwa von Peter-Alexis Albrecht - als »staatskritische Absolutheitsregel « in einer Laudatio für Burkhard Hirsch in Stellung gebracht wird.

Die Spontaneität wird auch nicht dadurch gemindert, dass man den Blick auf die Ebene der europäischen Rechtspflege richtet. Burkhard Hirsch macht das mit einer engagierten justizpolitischen Analyse deutlich. Gegenüber dem wissenschafts-pessimistischen Standpunkt von Albrecht liest sich das als unermüdlicher und kämpferischer Einsatz für eine strikte Rechtsstaatlichkeit - im Sinne eines Appells an den Gesetzgeber. Dass dieser Appell in der Europäischen Gerichtsbarkeit nicht ungehört verhallt, wird in der eher optimistischen richterlichen Entscheidungsperspektive von Dean Spielmann, Richter am Europäischen Gerichtshof für Menschenrechte, deutlich. Bezüglich eines umfassenden europäischen Grundrechteschutzes sollen die Europäerinnen und Europäer den EGMR nicht als »Gericht im Wartestand«, sondern als ein waches »Gericht im prüfenden Stand« betrachten. Stefan Braums Standpunkt ist zweigeteilt: Im Hinblick auf die Übermacht der europäischen Exekutive sieht er die Defizite der europäischen »Dritten Gewalt« gar als »Zerstörung juristischer Professionalität « an. Andererseits stimmen ihn die Versuche, Menschenrechte in der justiziellen Praxis zur Geltung zu bringen, durchaus hoffnungsvoll. Eindrucksvolle Beispiele als Beleg für diesen Optimismus, den er insofern mit Dean Spielmann teilt, werden von Braum angeführt.

Ein weiterer strafrechtlicher Ansatz ist Ausdruck reiner rechtsstaatlicher Empörung: Felix Herzog skandalisiert die Reaktion des nationalen Staates auf »terroristische Netzwerke« als »para-totalitäres Strafrechtsdenken«. Man muss es den Strafrechtlern nachsehen, wenn sie heftig reagieren, weil die Anlässe nicht weniger heftig sind. Menschenwürde ist aus dieser Sicht nur durch absolute Politiksperren, durch Absolutheitsregeln, durch scharfe begriffliche Abwehr zu schützen, nicht positiv herstellbar, sondern in ihrer Erosion nur durch juristische Empörung zeitweise aufhaltbar.

Das sieht der nationale Abwägungsneutralismus anders: Dieser schützt höchstens noch einen wie auch immer definierbaren Kern der Menschenwürde, in deren Peripherie zieht die Abwägung kräftig ein. Die Embryonen-Debatte lässt das deutlich werden. Die Verknüpfung von Würde und Lebensschutz, der das Bundesverfassungsgericht anhängt, dient hier als deutliche Kritik für eine »neue Position« (Felix Ekardt und Daniel Kornack), die über die Konzeption von »Diskursrationalität und Generationengerechtigkeit « die Würde letztlich in der Kommunikation auflöst. Die Conclusio aus dieser Sicht: »Und es kann auch niemals absolute Rechte geben, da Rechte stets

1 BVerfG (1 BvR 357/05), NJW 2006, $751 \mathrm{ff}$. 
untereinander kollidieren und sich dann gegenseitig beschränken müssen.« Wertungswidersprüche aufgrund des Einräumens unbeschränkbarer Rechte will auch Jörn Ahrens nicht riskieren. Von einem einheitlichen Gehalt des Menschenwürde-Begriffes könne keine Rede sein. »Rechtswissenschaft als Anthropotechnik « lasse sich in bioethischen Auseinandersetzungen zu keiner endgültigen Aussage führen. Sie könne höchstens vorgebrachten »Argumenten einen Rahmen« bereitstellen, »worin sich deren Gültigkeit bestimmen ließe.«

Vor dem Hintergrund des deutschen Streites zwischen den relativen und absoluten Würde-Theoretikern, liest sich die spanische Debatte über die Menschenwürde, die der deutschen Verfassung das Grundrecht der Menschenwürde nahezu neidet, fast wie eine Parteinahme für die absolute Position: »Ist die Menschenwürde kein Grundrecht, so wird die Person als Zurechnungszentrum vielfacher Grundrechte - aus der Sicht von Ignacio Gutiérrez Gutiérrez - »unvermeidlich fragmentiert [...]. Damit ist nach spanischem Verfassungsrecht verminderte Menschenwürde auch gebrochene Menschenwürde. So wird deutlich, dass verminderte und gebrochene Menschenwürde zu Empörung führen muss.«Vielleicht bringt uns diese rechtsvergleichende Erkenntnis dem Vorschlag von Naucke und Teubner näher, Menschenwürde nicht als positivistische Gewährleistung eines Souveräns anzusehen, sondern sie als »vor- und außerrechtliche« - der politischen Macht entzogene - absolute Politiksperre zu begreifen. Dann ist das Anwendungsbeispiel von Susanne Baer und Michael Wrase im letzten Beitrag, nämlich »Verfassungsrechtliche Perspektiven zum Kopftuch(-verbot) und der Gleichberechtigung «, vielleicht auch ein indirekter Fall der Menschenwürde - überlagert vom Gleichheitsgrundsatz des Grundgesetzes. 